08

\title{
Особенности гигантского магнитоимпедансного эффекта в пленочных структурах на основе пермаллоя в интервале температур, важных для практических приложений
}

\author{
(C) А.А. Членова, ${ }_{1}^{1}$ А.А. Моисеев, ${ }^{2}$ М.С. Деревянко, ${ }^{2}$ А.В. Семиров, ${ }^{2}$ В.Н. Лепаловский, ${ }^{1}$ Г.В. Курляндская ${ }^{1}$ \\ ${ }^{1}$ Уральский федеральный университет, \\ 620002 Екатеринбург, Россия \\ ${ }^{2}$ Иркутский государственный университет, \\ 664003 Иркутск, Россия \\ e-mail: chlenova.anna@gmail.com
}

(Поступило в Редакцию 19 апреля 2017 г.)

\begin{abstract}
Многослойные структуры на основе пленок $\mathrm{Fe}_{19} \mathrm{Ni}_{81}$ были получены методом ионно-плазменного распыления и исследованы на установке импедансной спектроскопии с температурной приставкой. В случае многослойной структуры $(\mathrm{Cu} / \mathrm{FeNi})_{5} / \mathrm{Cu} /(\mathrm{Cu} / \mathrm{FeNi})_{5}$ было обнаружено увеличение магнитоимпедансных соотношений для полного импеданса и его действительной части при увеличении температуры с 25 до $50^{\circ} \mathrm{C}$. Максимум гигантского магнитоимпедансного (ГМИ) соотношения полного импеданса $\Delta Z / Z=56 \%$ наблюдался на частоте $80 \mathrm{MHz}$, при чувствительности $18 \% / \mathrm{Oe}$, а максимум ГМИ соотношения действительной части $\Delta R / R=170 \%$ на частоте $10 \mathrm{MHz}$, при чувствительности $46 \% /$ Ое. Установлено, что намагниченность и электросопротивление на постоянном токе слабо меняются с температурой, поэтому в качестве наиболее вероятного механизма увеличения величины и чувствительности магнитоимпедансного эффекта был предложен механизм релаксации, связанный с магнитоупругой анизотропией.
\end{abstract}

DOI: $10.21883 /$ JTF.2018.01.45484.2303

\section{Введение}

Тонкопленочные многослойные структуры являются перспективными объектами для применения в качестве чувствительных элементов датчиков слабых магнитных полей, широко используемых в линиях автоматического контроля, магнитной дефектоскопии, магнитном биодетектировании и т.д. [1-3]. Особый интерес в этой связи ввиду высокой чувствительности по отношению к изменению внешнего магнитного поля вызывают сенсорные элементы, использующие в работе гигантский магнитоимпедансный эффект (ГМИ) [4-6]. Явление ГМИ заключается в изменении полного электросопротивления ферромагнитного образца, при протекании по нему переменного тока высокой частоты и приложении внешнего магнитного поля. Высокий эффект ГМИ наблюдается в образцах с низкой дисперсией локальных осей эффективной магнитной анизотропии и высокой динамической магнитной проницаемостью $[4,7]$.

Известно, что действенным способом изменения эффективной магнитной анизотропии является термическая обработка, различные виды которой очень широко используются для формирования требуемых свойств магнетиков [8-11]. Хотя вышесказанное прежде всего относится к достаточно высоким температурам, приводящим к термоактивации ряда физических процессов и изменениям структуры, хорошо известно, что и низкотемпературные термические обработки аморфных и нанокристаллических материалов могут оказывать заметное воздействие на особенности эффективной магнитной анизотропии [11]. Колебания температуры являются неотъемлемым фактором окружающей среды и важным параметром, определяющим условия работы конкретных детекторов магнитных полей. Если отрывочные данные о температурной зависимости ГМИ проволок, аморфных и нанокристаллических лент еще встречаются в литературе [12], то для пленочных структур за очень редким исключением [13] они практически отсутствуют.

Следует отметить, что большинство ранних исследований температурной зависимости ГМИ были сформулированы в терминах температурной стабильности эффекта, а для пленочных ГМИ элементов исследования проводились лишь на простейших структурах типа $\mathrm{FeNi} / \mathrm{Cu} / \mathrm{FeNi}$ с замкнутым магнитным потоком.

Максимальный ГМИ эффект наблюдается в конфигурации тонкопленочного элемента, который представляет собой многослойную структуру ферромагнетик/проводник/ферромагнетик с низкой дисперсией локальных осей поперечной эффективной магнитной анизотропии и высокой динамической магнитной проницаемостью. Для рабочих частот порядка нескольких десятков $\mathrm{MHz}$ толщины ферромагнитных слоев и центрального токовода должны составлять порядка $0.5 \mu \mathrm{m}[7,13]$. Однако хорошо известно, что получить магнитомягкие пленки пермаллоя такой толщины методом ионноплазменного распыления не удается из-за их перехода в „закритическое“ состояние $[10,14]$. Технологическим решением данной проблемы стало дополнительное наноструктурирование ферромагнитных слоев [15-17]. Исследования температурной зависимости ГМИ таких структур отсутствуют в научной литературе. 
Кроме того, в настоящее время создатели новых ГМИ материалов обсуждают концепцию перспективности ГМИ структур с особенностями симметрии, а именно, различной структурой ферромагнитных слоев „над“ и ,под“ центральным тоководом [18,19]. Предполагается, что исследование структур с различным количеством магнитных слоев позволит опытным путем создавать структуры с различными типами магнитного взаимодействия, различными механическими характеристиками и особенностями температурной зависимости ГМИ.

В настоящей работе исследовались магнитные свойства и температурные зависимости магнитного импеданса многослойных пленок типа $(\mathrm{Cu} / \mathrm{FeNi})_{5} / \mathrm{Cu} /(\mathrm{Cu} / \mathrm{FeNi})_{x}$ в интервале температур, важных для практических приложений.

\section{Методика проведения исследований}

Объектом данного исследования являлись многослойные пленки на основе пермаллоя Fe19Ni81, приготовленные методом ионно-плазменного распыления с использованием масок для получения элементов в виде полосок $11.0 \times 0.5 \mathrm{~mm}$. В ходе напыления для создания одноосной анизотропии магнитное поле в 100 Ое прикладывалось вдоль короткой стороны полоски сенсорного элемента. Образцы в зависимости от типа структуры были обозначены следующим образом: структура с симметричным расположением слоев относительно центрального проводящего медного слоя $(\mathrm{S})-[\mathrm{Cu}(3 \mathrm{~nm}) /$ $\mathrm{FeNi}(100 \mathrm{~nm})]_{5} / \mathrm{Cu}(500 \mathrm{~nm}) /[\mathrm{Cu}(3 \mathrm{~nm}) / \mathrm{FeNi}(100 \mathrm{~nm})]_{5}$; две несимметричные структуры AS - $[\mathrm{Cu}(3 \mathrm{~nm}) /$ $\mathrm{FeNi}(100 \mathrm{~nm})]_{5} / \mathrm{Cu}(500 \mathrm{~nm}) /[\mathrm{Cu}(3 \mathrm{~nm}) / \mathrm{FiNi}(100 \mathrm{~nm})]_{3} ; \quad$ и $\mathrm{A}-\mathrm{FeNi}(100 \mathrm{~nm})]_{5} / \mathrm{Cu}(3 \mathrm{~nm})$. Структуры S и А были напылены на стеклянную подложку, структуры AS на подложку из циклоолефинового сополимера [20].

Магнитные свойства (петли гистерезиса) пленочных структур $(5.0 \times 0.5 \mathrm{~mm})$ были измерены с помощью СКВИД-магнитометра при тех же температурах, что были использованы в исследованиях ГМИ. Измерение электросопротивления на постоянном токе $R_{d c}$ было проведено по стандартной методике для силы тока $10 \mathrm{~mA}$.

Измерение частотных и магнитополевых зависимостей модуля импеданса и его компонент были проведены на автоматизированном комплексе магнитоимпедансной спектроскопии в диапазоне частот $(f)$ переменного тока от 0.1 до $110 \mathrm{MHz}$ при воздействии внешнего аксиального магнитного поля напряженностью \pm 150 Ое [21]. Основу комплекса составляет прецизионный анализатор импеданса Agilent 4294A. Погрешность измерения импеданса и его компонент зависит от измеряемой величины, частоты переменного тока и составляет от 0.1 до $3 \%$. Внешнее квазистатическое магнитное поле создавалось парой откалиброванных катушек Гельмгольца, для компенсации геомагнитного и техногенного магнитных полей использовалась система из трех дополнительных пар катушек Гельмгольца, расположенных ортогонально.
Измерительная ячейка представляла собой основание из микалекса с закрепленными измерительными контактами из латуни с посеребрением, соединение которых с разъемом для подключения к анализатору выполнено многожильным медным проводом. Контакты в данном эксперименте с образцами на стеклянных подложках были расположены максимально близко к образцам, механическая фиксация и электрический контакт осуществлялись посредством проводящего клея. В ходе измерений была проведена процедура автоматической компенсации собственного импеданса измерительной ячейки, а также соединительных проводов, паразитный эффект которых значительно возрастает при увеличении частоты переменного тока.

Для исследований был выбран интервал температур от 25 до $50^{\circ} \mathrm{C}$, что обусловлено предполагаемым использованием многослойных пленочных структур с ГМИ эффектом в качестве чувствительного элемента датчиков слабых полей в интервале температур, важных для практических приложений, включая биосенсоры. Нагрев образцов в данной установке производится потоком воздуха при помощи термоблока, включающего в себя нагнетатель воздуха, нагревательный элемент, теплоизолированный воздуховод и двух термопар хромель-копель для измерения и контроля температуры потока. При исследовании образцов на гибкой подложке для исключения их деформации потоком воздуха в основании измерительной ячейки выполнено углубление, в котором располагаются образцы.

Относительное изменение полного импеданса (ГМИ соотношение) и его действительной компоненты во внешнем магнитном поле рассчитывалось по формулам: $\Delta Z / Z=100 \% \times\left[Z(H)-Z\left(H_{\max }\right)\right] / Z\left(H_{\max }\right), \Delta R / R=$ $=100 \% \times\left[R(H)-R\left(H_{\max }\right)\right] / R\left(H_{\max }\right)$, где $H_{\max }=150$ Oe. Максимальное значение для каждой частоты обозначалось как $\Delta Z / Z_{\max }$ для полного импеданса и $\Delta R / R_{\max }$ для его действительной компоненты. Важной характеристикой ГМИ эффекта является его максимальная чувствительность по отношению к внешнему магнитному полю. Чувствительность ГМИ рассчитывается по формуле $\mathrm{S}(\Delta Z / Z)=\Delta Z / Z / \Delta H$ или $\mathrm{S}(\Delta R / R)=\Delta R / R / \Delta H$, где $\Delta H=0.14 \mathrm{Oе}$. Максимально достижимое отношение для каждой конкретной частоты называется максимальной чувствительностью по отношению к внешнему магнитному полю. Для стабильной работы сенсорного элемента необходимо иметь участок линейной зависимости $\Delta Z / Z(H)$ порядка $1-3$ Ое, называемый рабочим интервалом, его центр - рабочая точка (РТ).

\section{Результаты исследований и их обсуждение}

В результате проведения магнитных исследований было установлено, что все образцы (S, AS, A) являются магнитомягкими ферромагнетиками с величиной коэрцитивности менее 1 Ое. Они также характеризуются 


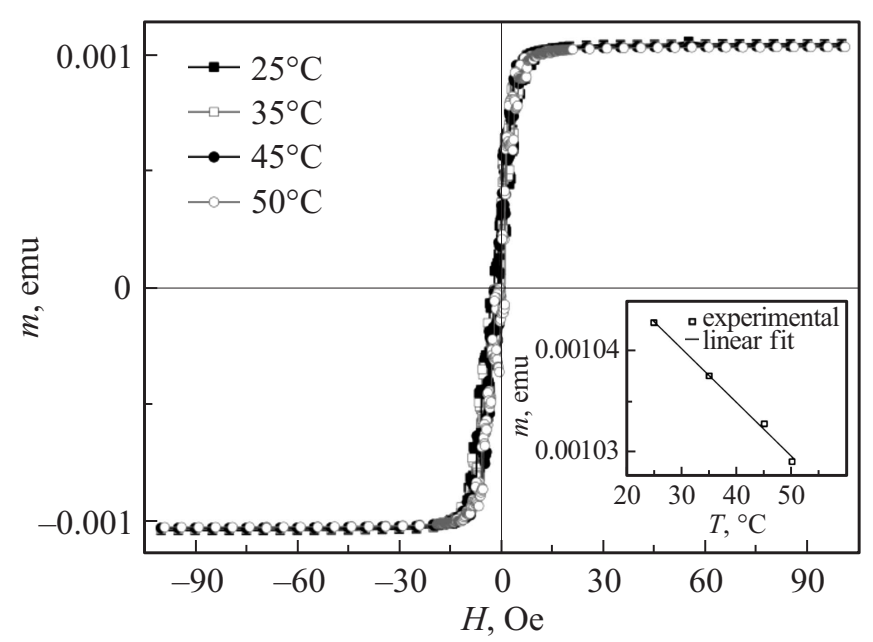

Рис. 1. Петли магнитного гистерезиса, полученные при помощи СКВИД-магнитометра, для структуры $\mathrm{S}$ при различных температурах, на вставке температурная зависимость магнитного момента в поле насыщения.

наличием выделенной оси легкого намагничивания, направление которой совпадает с направлением приложения внешнего магнитного поля в процессе осаждения образцов. В качестве примера рассмотрим температурную зависимость гистерезисных характеристик образца $\mathrm{S}$ (рис. 1). Увеличение температуры в интервале от 25 до 50 Ое приводит к очень незначительному уменьшению магнитного момента образца в поле насыщения $(m)$ (вставка рис. 1) и сохранению практически неизменной формы петли гистерезиса. Поле одноосной анизотропии во всех случаях составляло примерно 7 Ое.

Частотная зависимость максимума магнитоимпедансного соотношения для полного импеданса достаточно типична [7,17] для симметричной структуры (рис. 2,a), она имеет плато в интервале частот от 60 до $100 \mathrm{MHz}$. Несмотря на то что форма частотной зависимости $\Delta Z / Z_{\max }(f)$ меняется незначительно, для каждой фиксированной частоты увеличение температуры приводит к заметному возрастанию величины $\Delta Z / Z_{\max }$, что достаточно неожиданно в свете очень незначительного уменьшения магнитного момента образца. Частотная зависимость максимума магнитоимпедансного соотношения действительной части полного импеданса для симметричной структуры (рис. $2, b$ ) представляет собой убывающую функцию (обратите внимание на различие в шкале рис. 2, $a$ и $b$ ). При этом, несмотря на то что форма частотной зависимости $\Delta R / R_{\max }(f)$ также меняется незначительно, для каждой фиксированной частоты увеличение температуры приводит к заметному возрастанию величины $\Delta R / R_{\max }$.

Рассмотрим полевую зависимость полного импеданса и его действительной части (рис. 2, $c, d$ ) на частоте $80 \mathrm{MHz}$, для которой наблюдаются величины $\Delta Z / Z$ и $\Delta R / R$, близкие к абсолютно максимальным. Совершенно очевидно, что температурный отклик максимален в полях, близких к полю анизотропии, а при дальней- шем увеличении поля это различие достаточно быстро снижается. То есть основной вклад в температурную зависимость $\Delta Z / Z$ и $\Delta R / R$ соотношений вносит магнитное слагаемое. На частоте $80 \mathrm{MHz}$ максимальное соотношение для полного импеданса $\Delta Z / Z_{\max }$ при увеличении температуры на $25^{\circ} \mathrm{C}$ увеличивается на 18 , а соотношение $\Delta R / R_{\max }$ на $19 \%$. Фактически термочувствительность $\Delta Z / Z$ и $\Delta R / R$ ГМИ соотношений вблизи поля анизотропии многослойной структуры на основе пермаллоя можно использовать для создания датчика температуры на основе магнитоимпедансной зависимости действительной части импеданса $\Delta R / R$, работающего на достаточно низких частотах порядка $10 \mathrm{MHz}$. Как уже упоминалось ранее, чувствительность по отношению к внешнему магнитному полю является наиболее важным технологическим параметром. Чувствительность для ГМИ соотношения полного импеданса $\mathrm{S}(\Delta Z / Z)$ и его действительной части $\mathrm{S}(\Delta R / R)$ была рассчитана в поле 5 Ое (рис. 3 ).

Полученные зависимости отражают тенденции, близкие к тенденциям, описанным для частотных зависимостей на рис. 2, $a$ и $b$ : увеличение $\mathrm{S}(\Delta Z / Z)$ и уменьшение $\mathrm{S}(\Delta R / R)$ с ростом частоты, и увеличение чувствительностей обоих ГМИ соотношений с увеличением температуры. Следует отметить, что чувствительность ГМИ соотношения для полного импеданса на всех исследуемых частотах не превышала 10\%/Oе при комнатной температуре $\left(25^{\circ} \mathrm{C}\right)$ и $20 \% / \mathrm{Oe} \mathrm{при} \mathrm{темпе-}$ ратуре $50^{\circ} \mathrm{C}$, наибольшее увеличение чувствительности наблюдалось в частотном диапазоне от 60 до $80 \mathrm{MHz}$. Чувствительности ГМИ соотношения для действительной части полного импеданса (рис. $3, b$ ) представляют собой монотонно убывающие с частотой зависимости, имеющие наибольшее различие в области малых частот порядка $10 \mathrm{MHz}$. Повышение температуры приводит к заметному увеличению чувствительности: $\mathrm{S}(\Delta R / R)$ при температуре $50^{\circ} \mathrm{C}$ составила $46 \% /$ Ое на частоте $10 \mathrm{MHz}$. При сравнении температурной зависимости ГМИ соотношения полного импеданса и его действительной части структур с различными типами симметрии - S, AS и A (рис. 4), было очевидно, что абсолютным преимуществом обладала структура S. Образцы несимметричных структур показывали значительно меньшую величину самого эффекта и его чувствительности по отношению к внешнему полю. Кроме того, если для структуры $\mathrm{AS} \mathrm{c}$ меньшей степенью асимметрии наблюдалась достаточно типичная для многослойных пленок зависимость $\Delta Z / Z_{\max }(f)$ с максимумом, то для А структуры $\Delta Z / Z_{\max }(f)$ наблюдался незначительный рост величины $\Delta Z / Z_{\max }(f)$.

Последнее вполне можно интерпретировать как смещение максимума $\Delta Z / Z_{\max }(f)$ в область очень высоких частот, принимая во внимание тот факт, что многослойная структура А гораздо ближе по своим электродинамическим свойствам к структуре однослойной пленки, нежели к структуре типа ГМИ „сэндвич“. При этом обе зависимости $\Delta Z / Z_{\max }(f)$ для несимметричных 

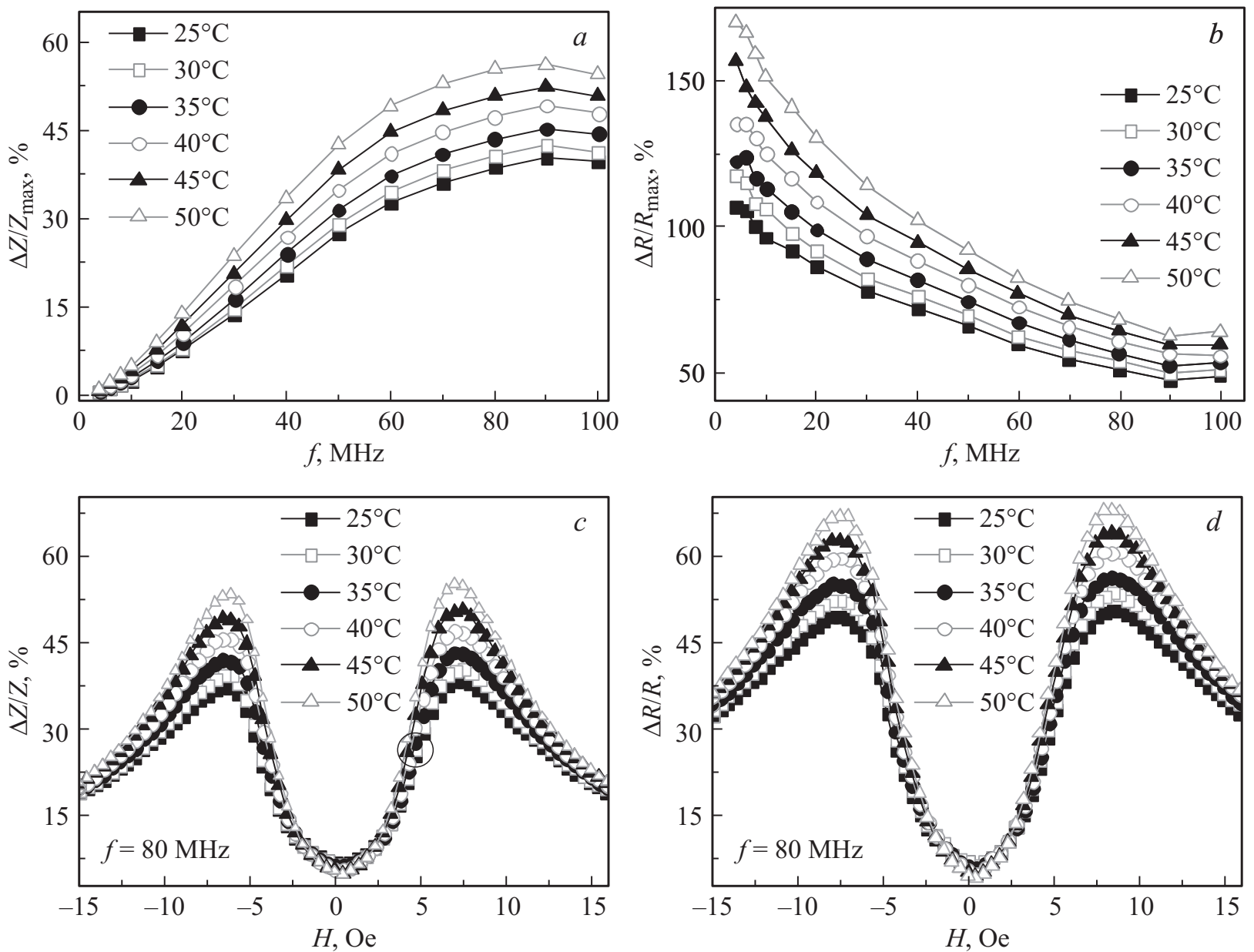

Рис. 2. Частотная зависимость максимального ГМИ соотношения для полного импеданса $(a)$ и его действительной части $(b)$ при разных температурах; полевая зависимость ГМИ соотношения полного импеданса (кружок соответствует рабочей точке) (c) и его действительной части $(d)$ при разных температурах на частоте $80 \mathrm{MHz}$. Данные приведены для структуры $\mathrm{S}$.
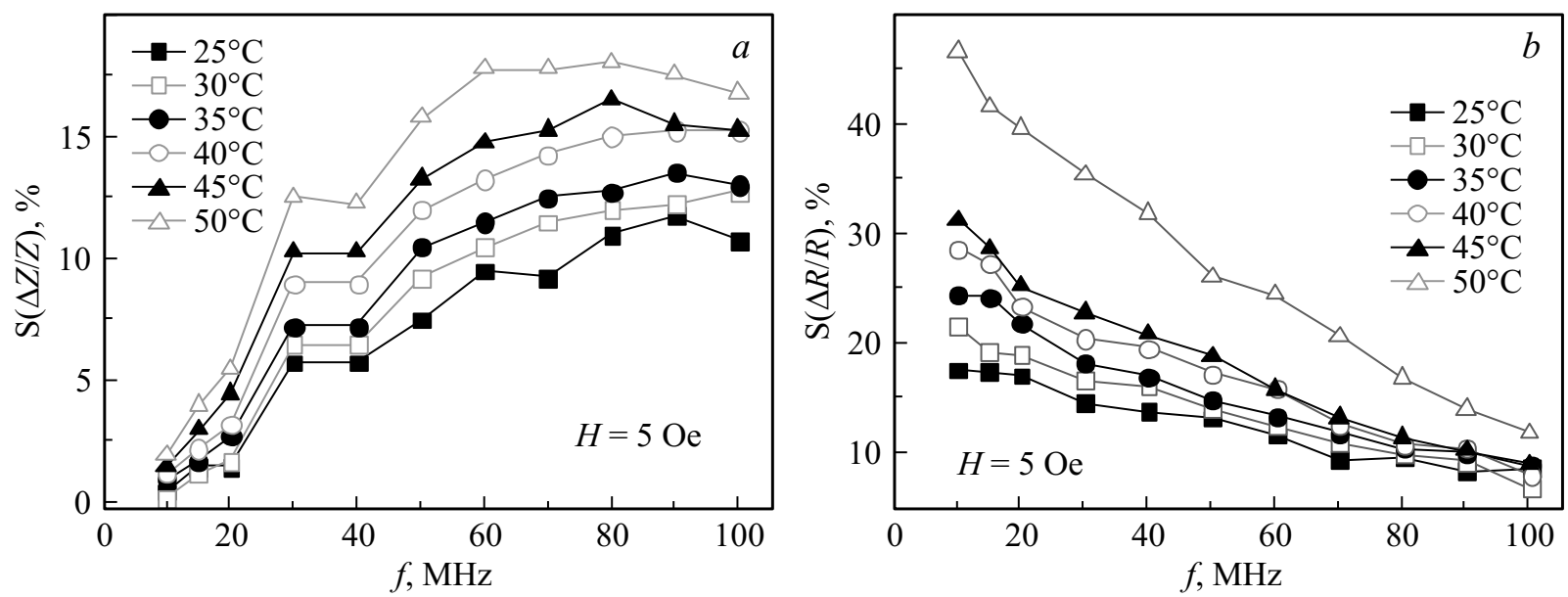

Рис. 3. Частотная зависимость чувствительности ГМИ соотношения полного импеданса $(a)$ и его действительной части $(b)$ при разных температурах для структуры $\mathrm{S}$ в рабочей точке $5 \mathrm{Oe}$.

структур похожи друг на друга тем, что демонстрируют очень слабую зависимость от температуры, то же можно сказать и для случая зависимостей $\Delta R / R_{\max }(f)$.
Для сравнения полевых зависимостей полного импеданса структур всех типов была выбрана частота $80 \mathrm{MHz}$, на которой ранее наблюдали максимум ГМИ 

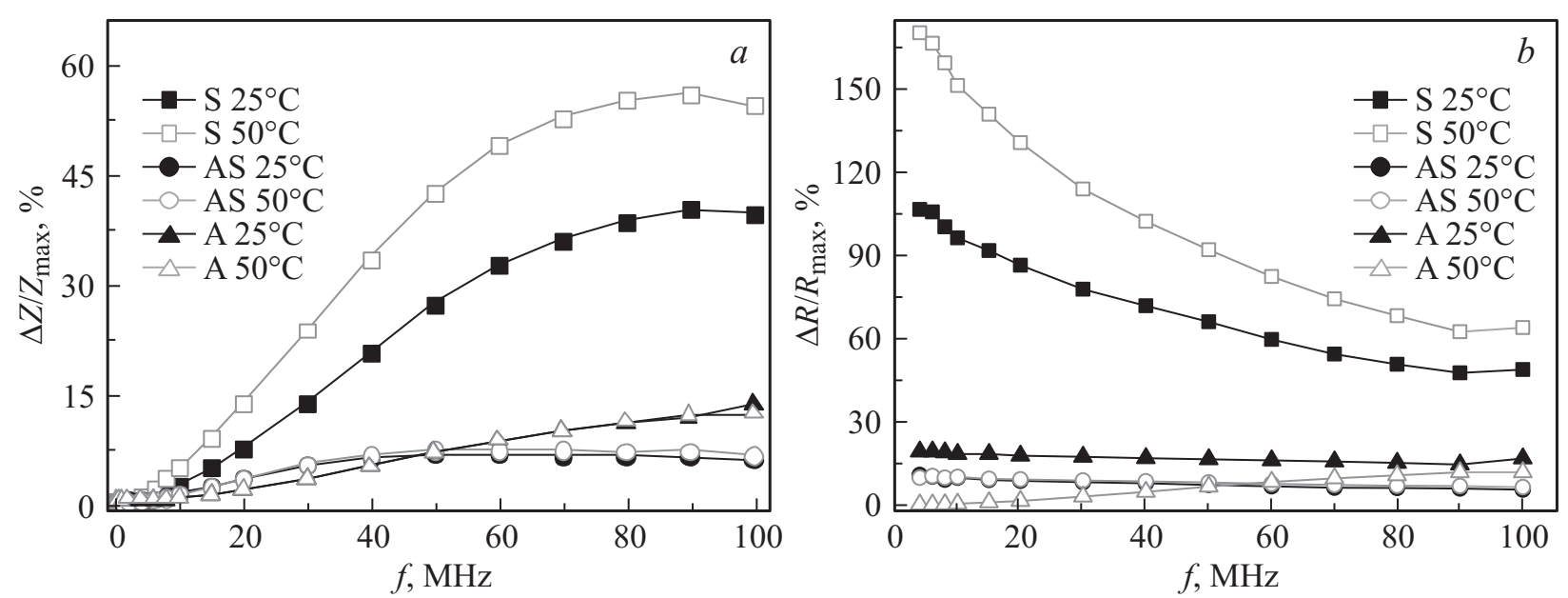

Рис. 4. Частотная зависимость максимального ГМИ соотношения полного импеданса $(a)$ и его действительной части $(b)$ при температурах 25 и $50^{\circ} \mathrm{C}$ для структур S, AS и A.
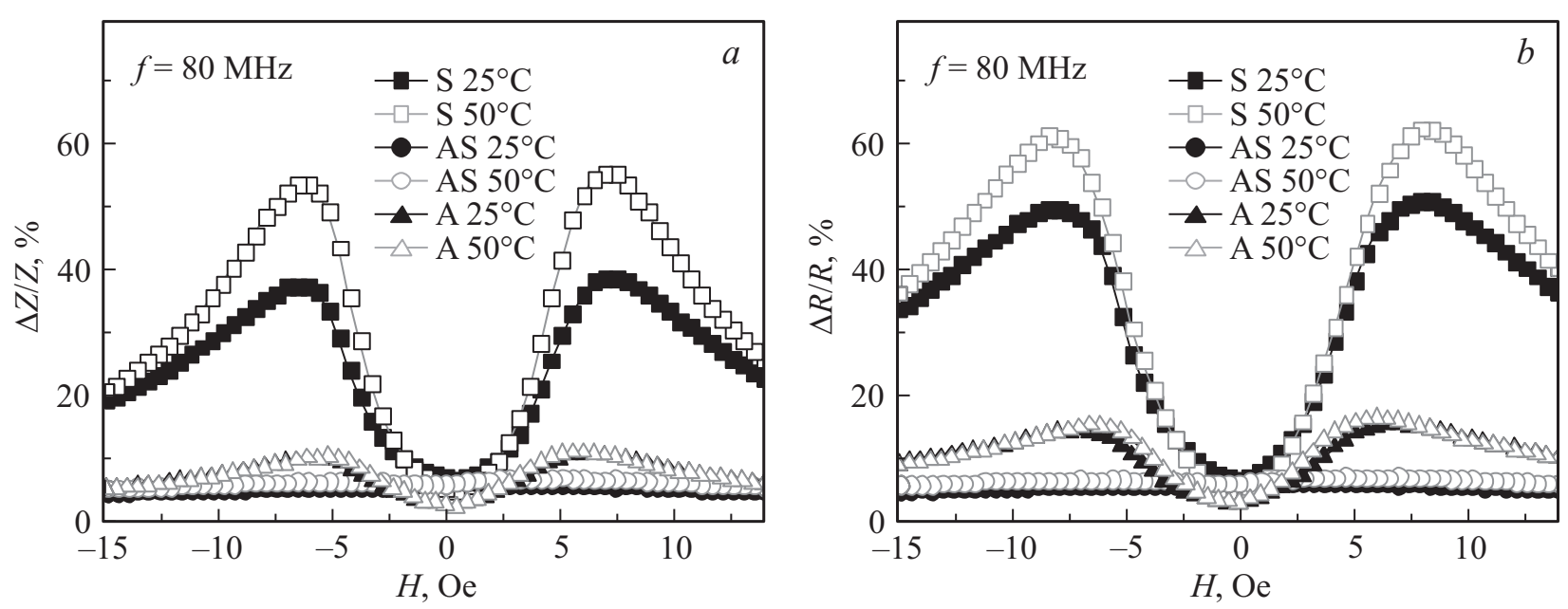

Рис. 5. Полевая зависимость ГМИ соотношения полного импеданса $(a)$ и его действительной части $(b)$ при температурах 25 и $50^{\circ} \mathrm{C}$ для структур $\mathrm{S}, \mathrm{AS}$ и А на частоте $80 \mathrm{MHz}$.

соотношения полного импеданса для структуры S. Для упрощения обсуждения на графиках представлены полевые зависимости ГМИ соотношений для двух крайних температур - комнатной и максимальной температуре $50^{\circ} \mathrm{C}$ (рис. 5). Выбранные для иллюстрации асимметричные структуры не позволяют обсуждать тонкие детали температурной зависимости ГМИ эффекта в силу его малости, но позволяют утверждать, что наблюдаемая в случае симметричной структуры сильная зависимость от температуры не всегда является типичной и требует обсуждения. $\Delta Z / Z$ и $\Delta R / R$ полевые зависимости для симметричной структуры характеризуются наличием двух выраженных максимумов в положительном и отрицательном поле, близком к полю анизотропии, измеренному с помощью СКВИД-магнитометрии. При этом пики на кривых $\Delta Z / Z(H)$ для разных температур примерно совпадают по своему положению, а пики на кривых $\Delta R / R(H)$ для высокой температуры несколько смещены в область бо́льших полей, что означает при проведении измерений на той же самой частоте несколько более высокую величину эффективной магнитной анизотропии.

С чем может быть связано наблюдаемое поведение? Ранее мы рассмотрели возможность изменения намагниченности магнитного слоя с температурой и обнаружили, что данный фактор не может быть решающим в понимании температурной зависимости эффекта ГМИ. Измерение электросопротивления на постоянном токе было проведено для структур S, AS, и А. Для удобства обсуждения был введен следующий параметр:

$$
D_{Y}=\frac{Y_{T=X^{\circ} \mathrm{C}}}{Y_{T=20^{\circ} \mathrm{C}}}
$$

который характеризует во сколько раз физическая величина $Y$ при температуре $X$ изменится по сравнению с той же величиной при температуре $25^{\circ} \mathrm{C}$ (рис. 6). 


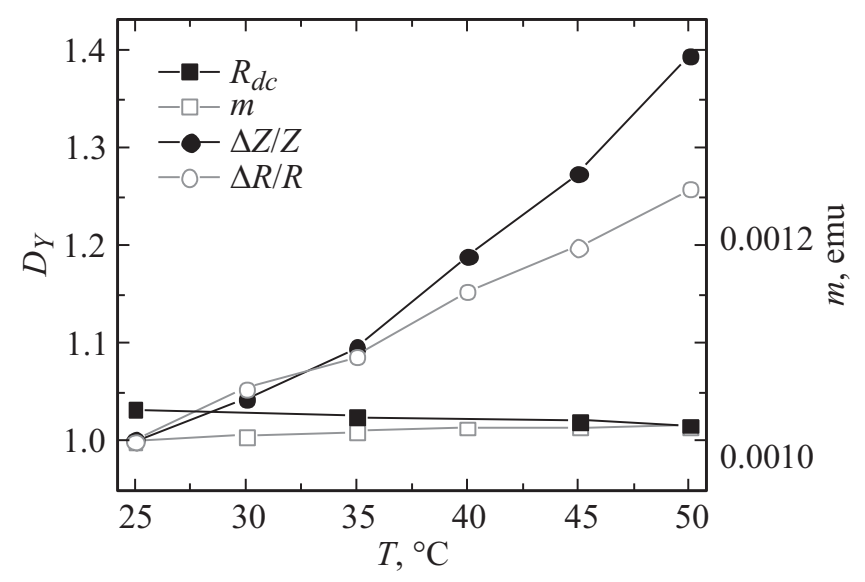

Рис. 6. Температурная зависимость $D_{Y}$, где $Y=R_{d c}, \Delta Z / Z$, $\Delta R / R$ и величины $m-$ намагниченности насыщения при температурах $25,35,45$ и $50^{\circ} \mathrm{C} . \Delta Z / Z$ и $\Delta R / R$ взяты в поле PT, при частоте $80 \mathrm{MHz}$.

Для всех структур $D_{R d c}$ оставалась порядка единицы и имела тенденцию к увеличению с ростом температуры на $2-4 \%$, тогда как $D_{\Delta Z / Z}$ возросла на $10 \%$ для структуры A, на 15\% для структуры AS и на 40\% для структуры S. Сравнение приведенных значений для электросопротивления на постоянном токе, величины магнитного момента и импедансных характеристик приведено для структуры $\mathrm{S}$ на рис. 6.

\section{Выводы}

Многослойные пленочные структуры на основе пленок Fe19Ni81 с особенностями симметрии были исследованы на усовершенствованной установке импедансной спектроскопии с температурной приставкой. Для симметричной многослойной структуры типа $(\mathrm{Cu} / \mathrm{FeNi})_{5} / \mathrm{Cu} /(\mathrm{Cu} / \mathrm{FeNi})_{5}$ было обнаружено увеличение магнитоимпедансных соотношений для полного импеданса и его действительной части при увеличении температуры с 25 до $50^{\circ} \mathrm{C}$. Максимум ГМИ соотношения составил $\Delta Z / Z=56 \%$ на частоте $80 \mathrm{MHz}$, при чувствительности $18 \% / \mathrm{Oe}$, а максимум ГМИ соотношения действительной части полного импеданса $170 \%$ на частоте $10 \mathrm{MHz}$, при чувствительности 46\%/Oе. Поскольку было установлено, что магнитная проницаемость и электросопротивление на постоянном токе слабо меняются с температурой в интервале от 25 до $50^{\circ} \mathrm{C}$, в качестве наиболее вероятного механизма увеличения величины и чувствительности магнитоимпедансного эффекта был предложен механизм частичной релаксации внутренних напряжений, приводящий к повышению динамической магнитной проницаемости многослойных пленочных структур.

Работа выполнена при поддержке гранта РФФИ мол_нр № 16-32-50054.

\section{Список литературы}

[1] Воробьев С.И., Шутылева О.В., Пазуха И.М., Чорноyс А.Н. // ЖТФ. 2014. Т. 84. Вып. 11. С. 66-71.

[2] Baselt D.R., Lee G.U., Natesan M., Metzger S.W., Sheehan P.E., Colton R.J. // Biosens. Bioelectr. 1998. Vol. 13. P. 731-739. http://dx.doi.org/10.1016/S0956-5663(98)00037-2

[3] Svalov A.V., Kurlyandskaya G.V., Vas'kovskiy V.O. // Appl. Phys. Lett. 2016. Vol. 108. P. 063504. http://dx.doi.org/10.1063/1.4942108

[4] Morikawa T., Nishibe Y., Yamadera H. // IEEE Trans. Magn. 1997. Vol. 33. N 5. P. 4367-4372. https://doi.org/10.1109/20.620448

[5] Panina L.V., Mohri K. // Sens. Actuators. A. 2000. Vol. 81. P. 71-77. http://dx.doi.org/10.1016/S0924-4247(99)00089-8

[6] Celegato F., Coisson M., Tiberto P., Vinai F. // J. Non-Cryst. Sol. 2008. Vol. 354. N 47-51. P. 5189-519. $\mathrm{http} / /$ dx.doi.org/10.1016/j.jnoncrysol.2008.08.022

[7] Волчков С.О., Лепаловский В.Н., Свалов А.В., Васьковский В.О., Курляндская Г.В. // Известия вузов. Физика. 2009. Т. 52. Вып. 10. С. 78-83.

[8] Malátek M., Ripka P., Kraus L. // Sens. Actuators. A: Phys. 2008. Vol. 147. N 2. P. 415-418. http://dx.doi.org/10.1016/j.sna.2008.05.016

[9] Radkovskaya A., Rakhmanov A.A., Perov N., Sheverdyaeva P., Antonov A.S. // JMMM. 2002. Vol. 249. P. 113116. http://dx.doi.org/10.1016/S0304-8853(02)00516-4

[10] Свалов А.В., Курляндская Г.В., Хаммер Х., Савин П.А., Тутынина О.И. // ЖТФ. 2004. Т. 74. Вып. 7. С. 62-65.

[11] Курляндская Г.В., Дмитриева Н.В., Потапов А.П., Лукшина В.А., Воронова Л.М., Гервасьева И.В., Бебенин Н.Г. // ФММ. 1997. Т. 83. № 5. С. 41-46.

[12] Semirov A.V., Derevyanko M.S., Bukreev D.A., Moiseev A.A., Kudryavtsev V.O., Safronov A.P. // JMMM. 2016. Vol. 415. P. 97-101. http://dx.doi.org/10.1016/j.jmmm.2016.01.055

[13] Mohri K., Uchiyama T., Panina L.V. // Sens. Actuators. A. 1997. Vol. 59. N 1-3. P. 1-8. http://dx.doi.org/10.1016/S0924-4247(97)80141-0

[14] Saito N., Fujiwara H., Sugita Y. // J. Phys. Soc. Jpn. 1964. Vol. 19. N 7. P. $1116-1125$. http://dx.doi.org/ 10.1143/JPSJ.19.1116

[15] Kurlyandskaya G.V., Elbaile L., Alves F., Ahamada B., Barrue R., Svalov A.V., Vas'kovskiy V.O. // J. Phys. Condens. Matter. 2004. Vol. 16. P. 6561-6568. http://dx.doi.org/10.1088/0953-8984/16/36/021

[16] Correa M.A., Bohn F., Chesman C., da Silva R.B., Viegas A.D.C., Sommer R.L. // J. Phys. D: Appl. Phys. 2010. Vol. 43. P. 295004-295007.

http://dx.doi.org/10.1088/0022-3727/43/29/295004

[17] Васьковский В.О., Савин П.А., Волчков С.О., Лепаловский В.Н., Букреев Д.А., Бучкевич А.А. // ЖТФ. 2013. Т. 83. Вып. 1. С. 110-116.

[18] Chlenova A., Svalov A., Kurlyandskaya G., Volchkov S. // JMMM. 2016. Vol. 415. P. 87-90. http://dx.doi.org/10.1016/j.jmmm.2016.01.035

[19] Антонов А.С., Бузников Н.А. // Письма в ЖТФ. 2016. Вып. 15. С. 86-94.

[20] Chlenova A.A., Melnikov G.Yu., Svalov A.V., Kurlyandskaya G.V. // AIP Conf. Proc. 2016. Vol. 1767. P. 020004. http://dx.doi.org/10.1063/1.4962588

[21] Семиров А.В., Моисеев А.А., Букреев Д.А., Кудрявщев В.О., Гаврилюк А.А., Захаров Г.В., Деревянко М.С. // НП. 2010. T. 20. № 2. C. 42-45. 